\title{
Biomarkers and prognostication in traumatic brain injury
}

\author{
Ganne S. Umamaheswara Rao
}

\begin{abstract}
A number of patients who suffer from mild head injury later on develop significant disabilities. Biomarkers help identify and quantify the extent of injury and help predict the possible functional outcome of the patients. There are promising candidate biomarkers for axonal injury (Tau) and astrocytic damage (glial fibrillary acidic protein and SI00 $\beta$ ) in traumatic brain injury. However, the biological significance of these markers cannot be confidently declared due to lack of studies with adequate sample size.
\end{abstract}

Key words: Biomarkers, prognostication, traumatic brain injury

\section{INTRODUCTION}

In recent years, there is an enhanced interest in mild head injury. A number of patients who suffer from mild head injury later on develop significant disabilities. It is necessary to know the extent of injury suffered by the brain in the initial phase. Biomarkers help identify and quantify the extent of injury and help predict the possible functional outcome of the patients. Accurate biochemical tests of axonal, neuronal and astroglial injury would be helpful to indicate whether head trauma caused an injury to the brain and to define when the injury has resolved. Studies have shown that returning to work too soon after a concussion without allowing time for recovery worsens the long-term outcome.

The advantages of blood biomarkers are:

Department of Neuroanaesthesia, National Institute of Mental Health and Neurosciences, Bengaluru, Karnataka, India

Address for correspondence:

Dr. Ganne S. Umamaheswara Rao, Department of Neuroanaesthesia, National Institute of Mental Health and Neurosciences,

Bengaluru - 560 029, Karnataka, India.

E-mail: gsuma123@yahoo.com

\begin{tabular}{|l|l|}
\hline \multicolumn{2}{|c|}{ Access this article online } \\
\hline Quick Response Code: & Website: \\
\hline & www.jnaccjournal.org \\
\cline { 2 - 3 } & \\
\hline
\end{tabular}

- They are cost-effective

- They involve minimally invasive sample collection

- They can provide a reference for neuroimaging referrals

- They may be used to identify various types of parenchymal brain injury and/or blood-brain barrier (BBB) damage

- Fluctuations in blood levels of biomarkers may help classify injury severity.

Some important questions that need to be addressed in evaluation of the biomarkers are:

- What is the origin of the protein of interest?

- Do cells of the BBB transport brain-derived proteins into the blood?

- Do physical activities such as sports-play and strenuous exercise affect blood levels of the protein of interest?

- Is the biomarker specific to damage associated with neurotrauma such as axonal distortion, glial cell activation and/or cell death within the neurovascular unit?

- When does a protein of interest reach its peak concentration in the blood?

This is an open access article distributed under the terms of the Creative Commons Attribution-NonCommercial-ShareAlike 3.0 License, which allows others to remix, tweak, and build upon the work non-commercially, as long as the author is credited and the new creations are licensed under the identical terms.

For reprints contact: reprints@medknow.com

How to cite this article: Umamaheswara Rao GS. Biomarkers and prognostication in traumatic brain injury. J Neuroanaesthesiol Crit Care 2017;4:S2-5. 
Mild head injury does not produce gross pathology that can be visualised on a computed tomography (CT) scan but causes neurological symptoms which resolve in about a week to 2 weeks' time. However, about $15 \%$ of patients have persistent cognitive dysfunction. ${ }^{[1]}$ Although axonal disconnection occurs rarely at the time of injury, the rapid stretching of axons causes an unregulated outflux of $\mathrm{K}^{+}$and influx of $\mathrm{Na}^{+[2]}$ which, in turn, causes an increase in intra-axonal $\mathrm{Ca}^{2+}$ concentrations. $\mathrm{Ca}^{2+}$ stimulates protease calpain, which causes proteolysis of cytoskeleton. $\mathrm{Ca}^{2+}$ also stimulates n-methyl-d-aspartate receptors and the associated injury. ${ }^{[3]}$

In addition to these ionic disturbances, ultrastructural studies of axons show mechanical breakage and buckling of microtubules at the time of injury, which can trigger progressive microtubule disassembly. ${ }^{[4]}$ Studies using advanced magnetic resonance imaging (MRI) techniques, such as diffusion tensor imaging, show that the extent of white matter abnormalities after mild traumatic brain injury (TBI) correlates with the severity of postconcussion cognitive problems.

Biomarkers can be classified into those identified in cerebrospinal fluid (CSF) and those that are identified in the blood.

\section{CEREBROSPINAL FLUID BIOMARKERS}

CSF composition reflects the changes that take place in the brain. CSF biomarkers of brain injury include proteins that indicate BBB integrity and neuroinflammation, as well as axonal, neuronal and astroglial damage.

\section{Markers of blood-brain barrier integrity}

The CSF: serum albumin ratio is a standard biomarker of BBB function. An increase in this ratio indicates BBB damage, which is found in patients with various central nervous system (CNS) disorders ${ }^{[5]}$ Neuroinflammatory response to severe TBI increases CSF: serum ratio. The ratio is increased in severe $\mathrm{TBI}^{[6]}$ and not in mild TBI. ${ }^{[7]}$

\section{Markers of neuroinflammation}

In general, levels of inflammatory proteins, such as interleukin-6 (IL-6), IL-8 and IL-10, are increased in CSF in response to severe TBI. ${ }^{[8-10]}$ The magnitude of the rise correlates with the patient's outcome, and in some studies also with the extent of BBB dysfunction, as shown by the CSF: serum albumin ratio. However, one of the fallacies with these markers is that they are not brain specific. They may be liberated in the peripheral tissues and slowly seep into the CSF.

\section{Markers of acute axonal injury}

The two best-established CSF biomarkers of axonal injury are total tau protein and neurofilament light polypeptide (NFL). Tau protein is highly expressed in thin, nonmyelinated axons of cortical interneurons, whereas NFL is most abundant in the large-calibre myelinated axons that project into deeper brain layers and the spinal cord. The consensus in the literature is that total tau protein levels in ventricular CSF correlate with lesion size and clinical outcome in patients with TBI; high levels are an indication of more severe injury. ${ }^{[11,12]}$ Neurofilaments are composed of neuron-specific intermediate filaments. Each intermediate filament consists of one light subunit (NFL) plus either a medium subunit or a heavy subunit (NFH), arranged head to tail. High levels of phosphorylated $\mathrm{NFH}$ have been demonstrated in the ventricular CSF of patients with severe TBI. The degree of rise in NFL is larger than tau in TBI. NFL in CSF seems to be the most sensitive biomarker of axonal injury. ${ }^{[13]}$

\section{Markers of acute neuronal injury}

Neuron-specific enolase (NSE) is a glycotic enzyme mostly present in neuronal cell body. NSE levels in CSF correlate with mortality in TBI, Glasgow Coma Scale and Glasgow Outcome Scale. ${ }^{[14]}$ Since NSE is also abundantly present in erythrocytes, its levels are highly sensitive to haemolysis. Therefore, contamination of CSF sample with blood might greatly influence the NSE measurement.

\section{Markers of acute astroglial injury}

$\mathrm{S} 100 \beta$ is an intracellular protein but can be released into the extracellular space. Since $S 100 \beta$ does not cross an intact BBB, elevated serum levels of $S 100 \beta$ following TBI have been attributed to BBB permeability. The effects of $S 100 \beta$ appear to be concentration dependent. It is protective and trophic at low concentrations but toxic and pro-apoptotic at high concentrations.

S100 $\beta$ has been thought to be specific for astroglia but has been detected in oligodendrocytes and adipocytes. Patients with mild TBI have slightly elevated levels of $S 100 \beta$ after the injury, but the increase is not as much pronounced as tau and NFL. Similar results have been reported for glial fibrillary acidic protein (GFAP), a CNS-specific protein that is almost exclusively expressed in astroglia. They are slightly elevated after mild TBI, but the CSF levels of this protein, when added to the clinical data, improved the power of outcome prediction. ${ }^{[15]}$

\section{Markers of amyloid-related processes}

Amyloid precursor protein (APP) accumulates in neurons and axons after brain trauma that causes axonal damage. APP accumulates in TBI after about 2-3 h of injury. In addition, intra-axonal accumulation of $A \beta$ is common in TBI patients. Aggregation of $A \beta$ is associated with the development of Alzheimer's disease (AD). A $\beta$ is released into the tissue surrounding damaged axons, where it leads to plaque formation. Ventricular CSF levels of $A \beta 40$ and $A \beta 42$ increase during the $1^{\text {st }}$ week after 
head trauma in patients with severe TBI. ${ }^{[16]}$ However, samples of CSF from lumbar puncture did not show changes in $A \beta 40$ and $A \beta 42$. Thus, the $A \beta$ levels in CSF samples obtained by lumbar puncture are less sensitive to the effects of mild TBI.

\section{BLOOD BIOMARKERS}

The proteins that are expressed in brain are also detectable in low concentrations in the blood. The low concentration of the biomarkers in peripheral blood is a technical challenge to the use of most standard immunoassays. However, the number of biomarkers of brain injury in peripheral blood is steadily increasing as the analytical tools for their detection become ever more sensitive.

$\mathrm{BBB}$ is a barrier to the transfer of protein expressed in the brain into the blood. Impaired BBB integrity, as seen in severe TBI, can increase the levels of brain-derived proteins in the blood. Some potential biomarkers undergo proteolytic degradation and some of them might be cleared by liver and kidney. For these reasons, the blood concentrations of the biomarkers are bound to be less than that of CSF concentration.

\section{Markers of astroglial injury}

Normal blood levels of $\mathrm{S} 100 \beta$ are approximately $0.05 \mathrm{ng} / \mathrm{ml}$. These levels can increase to nearly $5 \mathrm{ng} / \mathrm{ml}$ after severe TBI. Increased serum levels of $\mathrm{S100} \beta$ have been observed within $24 \mathrm{~h}$ of severe TBI and strongly correlate with mortality. ${ }^{[17,18]}$ The levels of S100 $\beta$ and GFAP in serum correlate with Glasgow Coma Scale scores and neuroradiological findings at hospital admission. ${ }^{[19]}$ Since $S 100 \beta$ can be raised from fractured bones or injured skeletal muscle, its reliability seems to be low.

GFAP is the principal structural protein of cytoskeletal intermediate filaments expressed by astrocytes. Serum GFAP levels rise post-injury as a result of its release from damaged astrocytes. Increases in serum GFAP act as a surrogate marker for astrocytic injury. Blood levels of GFAP are $0.012 \mathrm{ng} / \mathrm{ml}$ in health. They increase significantly $(4.52 \pm 8.69 \mathrm{ng} / \mathrm{ml}$ compared to healthy controls $0.061 \pm 0.044 \mathrm{ng} / \mathrm{ml}$ ) in severe brain injury and predict mortality, recovery, outcome and intracranial lesion. ${ }^{[20-23]}$ GFAP is not expressed by any extracerebral tissue. Therefore, it is a more reliable biomarker.

\section{Markers of axonal and neuronal injuries}

Some of the important biomarkers in the blood are NSE, myelin basic protein (MBP) and hyperphosphorylated NFH. Enolase is a crucial catabolic enzyme that converts 2-phosphoglycerate to phosphoenolpyruvate in the glycolytic pathway for adenosine triphosphate production. NSE reaches the bloodstream through the glymphatic system. Serum NSE levels in normal individuals are around $10 \mathrm{ng} / \mathrm{ml}$. Values $>21.7 \mathrm{ng} / \mathrm{ml}$ have been reported after TBI. Moreover, NSE levels have a high sensitivity to predict death $(85 \%)$ or poor outcome (80\%) 6 months after injury. ${ }^{[24]}$ The increase in the levels of NSE in CSF observed in response to lysis of erythrocytes is a major limitation of this biomarker. MBP levels have been shown to be more specific markers of TBI than NSE levels (specificity $96 \%$ vs. $64 \%$ ), but their sensitivity is less ( $44 \%$ vs. $71 \%$ ). NHF levels increased over the 6 consecutive days in TBI patients who died.

\section{Markers of amyloid-related processes}

Tau is predominantly expressed by neurons and preferentially localised within axons. Serum levels of tau protein could be measured by an ultrasensitive digital immunoassay technique with a lower limit of detection of $0.02 \mathrm{pg} / \mathrm{ml}$. The values ranged from $<10 \mathrm{pg} / \mathrm{ml}$ to $400 \mathrm{pg} / \mathrm{ml}$ in patients who were resuscitated after cardiac arrest. This sensitive assay method will be useful in assessing the severity of TBI. Serum T-Tau levels were increased in mild TBI patients $(188 \pm 210 \mathrm{pg} / \mathrm{ml})$ compared to healthy controls $(86 \pm 48 \mathrm{pg} / \mathrm{ml}) ;^{[25]}$ correlational analyses between CT imaging and serum T-Tau levels among mild TBI patients revealed that T-Tau successfully differentiated patients with intracranial injury $(307 \pm 246 \mathrm{pg} / \mathrm{ml})$ from those without intracranial injury $(77 \pm 61 \mathrm{pg} / \mathrm{ml})$.

\section{Emerging blood biomarkers}

Spectrin degradation products from CSF samples of severe TBI patients correlated with the Glasgow Coma Scale scores and improved the prediction of outcomes. Levels of spectrin breakdown products in CSF were measured together with those of another potential marker, ubiquitin carboxyl-terminal hydrolase isoenzyme L1, a deubiquitinase that is highly expressed in neurons. The levels of these two markers contributed significantly to the outcome prediction model. ${ }^{[26]}$

\section{CONCLUSION}

There are promising biomarkers for axonal injury (Tau) and astrocytic damage (GFAP and S100 $\beta$ ) in TBI. However, the biological significance of these markers cannot be confidently declared due to lack of studies with adequate sample size.

\section{Financial support and sponsorship Nil.}

\section{Conflicts of interest}

There are no conflicts of interest.

\section{REFERENCES}

1. Williams $W H$, Potter $S$, Ryland $H$. Mild traumatic brain injury and Postconcussion syndrome: A neuropsychological perspective. J Neurol Neurosurg Psychiatry 2010;81:1116-22. 
2. Johnson VE, Stewart W, Smith DH. Axonal pathology in traumatic brain injury. Exp Neurol 2013;246:35-43.

3. Barkhoudarian G, Hovda DA, Giza CC. The molecular pathophysiology of concussive brain injury. Clin Sports Med 2011;30:33-48, vii-iii.

4. Tang-Schomer MD, Patel AR, Baas PW, Smith DH. Mechanical breaking of microtubules in axons during dynamic stretch injury underlies delayed elasticity, microtubule disassembly, and axon degeneration. FASEB J 2010;24:1401-10.

5. Blennow K, Hampel H, Weiner M, Zetterberg H. Cerebrospinal fluid and plasma biomarkers in Alzheimer disease. Nat Rev Neurol 2010;6:131-44.

6. Csuka E, Morganti-Kossmann MC, Lenzlinger PM, Joller H, Trentz O, Kossmann T. IL-10 levels in cerebrospinal fluid and serum of patients with severe traumatic brain injury: Relationship to IL-6, TNF-alpha, TGF-beta1 and blood-brain barrier function. J Neuroimmunol 1999;101:211-21.

7. Zetterberg H, Hietala MA, Jonsson M, Andreasen N, Styrud E, Karlsson I, et al. Neurochemical aftermath of amateur boxing. Arch Neurol 2006;63:1277-80.

8. Kossmann T, Hans VH, Imhof HG, Stocker R, Grob P, Trentz O, et al. Intrathecal and serum interleukin- 6 and the acute-phase response in patients with severe traumatic brain injuries. Shock 1995;4:311-7.

9. Buttram SD, Wisniewski SR, Jackson EK, Adelson PD, Feldman K, Bayir $\mathrm{H}$, et al. Multiplex assessment of cytokine and chemokine levels in cerebrospinal fluid following severe pediatric traumatic brain injury: Effects of moderate hypothermia. J Neurotrauma 2007;24:1707-17.

10. Shiozaki T, Hayakata T, Tasaki O, Hosotubo H, Fuijita K, Mouri $\mathrm{T}$, et al. Cerebrospinal fluid concentrations of anti-inflammatory mediators in early-phase severe traumatic brain injury. Shock 2005;23:406-10.

11. Zemlan FP, Jauch EC, Mulchahey JJ, Gabbita SP, Rosenberg WS, Speciale SG, et al. C-tau biomarker of neuronal damage in severe brain injured patients: Association with elevated intracranial pressure and clinical outcome. Brain Res 2002;947:131-9.

12. Ost M, Nylén K, Csajbok L, Ohrfelt AO, Tullberg M, Wikkelsö C, et al. Initial CSF total tau correlates with 1-year outcome in patients with traumatic brain injury. Neurology 2006;67:1600-4.

13. Neselius S, Brisby $\mathrm{H}$, Theodorsson A, Blennow $\mathrm{K}$, Zetterberg $\mathrm{H}$, Marcusson J. CSF-biomarkers in Olympic boxing: Diagnosis and effects of repetitive head trauma. PLoS One 2012;7:e33606.

14. Ross SA, Cunningham RT, Johnston CF, Rowlands BJ. Neuron-specific enolase as an aid to outcome prediction in head injury. Br J Neurosurg 1996;10:471-6.

15. Czeiter E, Mondello S, Kovacs N, Sandor J, Gabrielli A, Schmid $\mathrm{K}$, et al. Brain injury biomarkers may improve the predictive power of the IMPACT outcome calculator. J Neurotrauma 2012;29:1770-8.

16. Olsson A, Csajbok L, Ost M, Höglund K, Nylén K, Rosengren L, et al. Marked increase of beta-amyloid(1-42) and amyloid precursor protein in ventricular cerebrospinal fluid after severe traumatic brain injury. J Neurol 2004;251:870-6.

17. Goyal A, Failla MD, Niyonkuru C, Amin K, Fabio A, Berger RP, et al. S100b as a prognostic biomarker in outcome prediction for patients with severe traumatic brain injury. J Neurotrauma 2013;30:946-57.

18. Korfias S, Stranjalis G, Boviatsis E, Psachoulia C, Jullien G, Gregson B, et al. Serum S-100B protein monitoring in patients with severe traumatic brain injury. Intensive Care Med 2007;33:255-60.

19. Pelinka LE, Kroepfl A, Leixnering M, Buchinger W, Raabe A, Redl H. GFAP versus S100B in serum after traumatic brain injury: Relationship to brain damage and outcome. J Neurotrauma 2004;21:1553-61.

20. Vos PE, Jacobs B, Andriessen TM, Lamers KJ, Borm GF, Beems T, et al. GFAP and S100B are biomarkers of traumatic brain injury: An observational cohort study. Neurology 2010;75:1786-93.

21. Lumpkins KM, Bochicchio GV, Keledjian K, Simard JM, McCunn M, Scalea T. Glial fibrillary acidic protein is highly correlated with brain injury. J Trauma 2008;65:778-82.

22. Nylén K, Ost M, Csajbok LZ, Nilsson I, Blennow K, Nellgård B, et al. Increased serum-GFAP in patients with severe traumatic brain injury is related to outcome. J Neurol Sci 2006;240:85-91.

23. Vos PE, Lamers KJ, Hendriks JC, van Haaren M, Beems T, Zimmerman $\mathrm{C}$, et al. Glial and neuronal proteins in serum predict outcome after severe traumatic brain injury. Neurology 2004;62:1303-10.

24. Bulut M, Koksal O, Dogan S, Bolca N, Ozguc H, Korfali E, et al. Tau protein as a serum marker of brain damage in mild traumatic brain injury: Preliminary results. Adv Ther 2006;23:12-22.

25. Kövesdi E, Lückl J, Bukovics P, Farkas O, Pál J, Czeiter E, et al. Update on protein biomarkers in traumatic brain injury with emphasis on clinical use in adults and pediatrics. Acta Neurochir (Wien) 2010;152:1-17.

26. Mondello S, Robicsek SA, Gabrielli A, Brophy GM, Papa L, Tepas J, et al. all-spectrin breakdown products (SBDPs): Diagnosis and outcome in severe traumatic brain injury patients. J Neurotrauma 2010;27:1203-13. 